\title{
Safety and geometric aspects of humps and road crossings
}

\author{
E. De Winne $e^{1,2}$ \& P. De Winne ${ }^{1,3}$ \\ ${ }^{I}$ Faculty of Engineering, Department Civil Techniques, Ghent University, \\ Belgium \\ ${ }^{2}$ Ministry of Mobility and Public Works, Belgium \\ ${ }^{3}$ Project Engineer, Road and Traffic Administration, \\ Ministry of Mobility and Public Works, Belgium
}

\begin{abstract}
A speed hump is a local rising of a public road, formed as a sinusoidal, and meant to force drivers physically to decrease their speed. A plateau is also meant to moderate the speed, but this is a flat rising with gradual slopes. Because of the large diversity in legally normalized construction types, the geometric control of these raised constructions is a complex matter. Moreover, because of the typical low to the ground form of a flatbed truck, problems arise when the road crossings shows a round form. The objective of this study is to find a surveying method to collect geometric data, in order to inspect speed humps, plateaus and road crossings. Depending on the categorisation of the different sorts of roads, and the construction principles for flatbed trucks, the work also deals with the theoretical definition of the possibility of passing the road crossings with flatbed trucks. The problem is extrapolated to several successive obstacles and is also applied on traffic thresholds and traffic plateaus, which are also considered as obstacles for flatbed trucks. The paper discusses a surveying and processing method in design, which makes use of a surveyor's level and proposes the development of new surveying methods namely an adapted method for a level, a method for a total station and a method for a GPS instrument. Finally, the results of an interesting comparison between the different methods by means of surveys on site are presented and the results are applied on some practical examples.

Keywords: traffic safety, road crossings, traffic humps, traffic plateaus, rumple strips, flatbed trucks, speed reduction.
\end{abstract}




\section{Introduction}

The need often arises to discourage motorists from travelling at high speeds along certain roads or using roads that are not suitable for through traffic as short cuts. Of the various ways of achieving this, one possibility is the construction of humps across the road. Speed control humps have become increasingly common on roads throughout the world.

Among the various configurations of pavement treatments such as bars, rumple strips, raised junctions and so on, the speed hump and plateau are most frequently used in Belgium and indicated in one term as raised constructions.

The applications are mostly on residential streets, working well with curb extensions, and not typically on major roads, not on bus routes or primary emergency response routes, not at intersections or on grades greater than $8 \%$.

A traffic hump or plateau can be considered as an obstacle for flatbed trucks as well. Actually, a traffic hump can be considered as a hill, consisting of one arc. A traffic plateau is just like a hill, consisting of an unevenness. This means that in existing state situations, the possibility of passing can be calculated. The design situations are important. If a designer wants to design a hump and a plateau on a road, used by flatbed trucks, he has two problems. First he wants the hump as flat as possible, so that the flatbed truck doesn't get fixed, but on the other hand, he has to follow the geometrical rules of the Belgian government.

Belgium has a complex legislation for raised constructions. Because of the large diversity in legally normalized construction types, the geometric control of these structures is a complex matter. Therefore accurate measurement methods are required to check conformity with legal regulation. For flatbed trucks as well, the construction must be as flat as possible, and responding to governmental rules.

The design situations need some safe speed advisories, and bicyclists prefer that it doesn't cover or cross a bike lane.

\section{Geometrical form}

- A traffic hump is a local rising on the public road, in the form of a sinus line, meant to force drivers physically to reduce the speed of their vehicle. Its length profile has been meant to cause a discomfort, which rises in function of an increasing speed while driving over it. The increase of the vertical acceleration must be maximal for a speed nearly $30 \mathrm{~km}$ per hour.

- A traffic plateau is a flat rising of the public road with slopes, which are in a straight line of in a sinus form finished. The form can change using another height, slope or length.

It is sometimes difficult to construct humps and plateaus precisely, and they may need to specify a construction tolerance on height. Often they need advance warning signs before the first hump in series and 
warning signs or object markers at the hump. Typically pavement markings are zigzags, shark's tooth, chevron, zebra... Tapar edges near curbs are necessary to allow a gap for drainage.

\section{Measure methods}

\subsection{With a surveyor's level}

The Belgian Road Research Centre (BRRC) has developed a surveying and processing method based on a level to measure raised constructions The method is split up for speed humps on the one hand and plateaus on the other hand, because of the separate dictated rules for their construction and their technical prescriptions laid down by the Belgian law. Naturally, there are still many points of resemblance between the methods.

The measurement method exists of different stages. The first step is to determine the position of the length profiles. Therefore a wheel-base of 1,40 m of an average passenger car is assumed. The length profiles are thus positioned on the wheel-tracks. The determination of 2 length profiles per lane, by measuring at the beginning and the end of the raised construction, the widths b1, $\mathrm{b} 2(=\mathrm{b} 1 / 2), \mathrm{b} 3(=\mathrm{b} 2 / 2$, and put out $0,70 \mathrm{~m}$ at both side from line $\mathrm{b} 3$, is illustrated in Fig. 1.

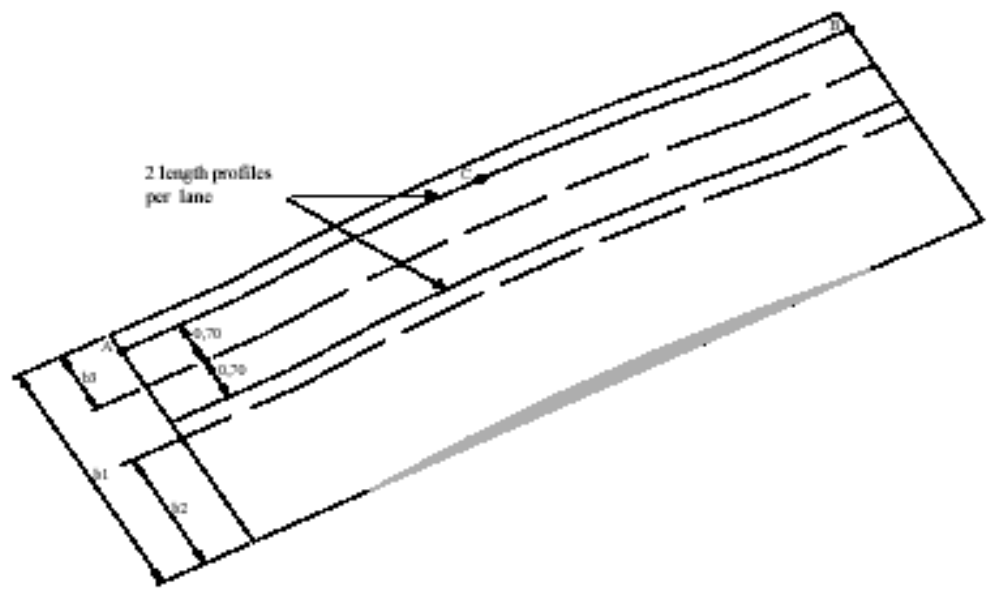

Figure 1: Determination of the position of the length profiles.

In a next step 17 points (for a speed hump) or 13 points (for a plateau) on each length profile are defined with a measuring-tape and indicated on the surface with chalk. These points are measured with the level. The number of points to be measured per length profile for a speed hump is provided by the Belgian law, namely 17 points for a regular speed hump of $4,80 \mathrm{~m}$ (so that the speed hump is divided in 16 equal parts of $0,30 \mathrm{~m}$ ). However, the number of 
measuring points for a plateau is not specified in the law. The number of 13 points is chosen by the BRRC and follows an analogous argument to divide the slopes of a plateau in equal parts of proximally $0,30 \mathrm{~m}$. (This means for slopes of 3,80 $\mathrm{m}$ in 12 parts.) Even though there are shorter slopes allowed, they keep 13 points in order to process easily the features in one and the same data processing program.

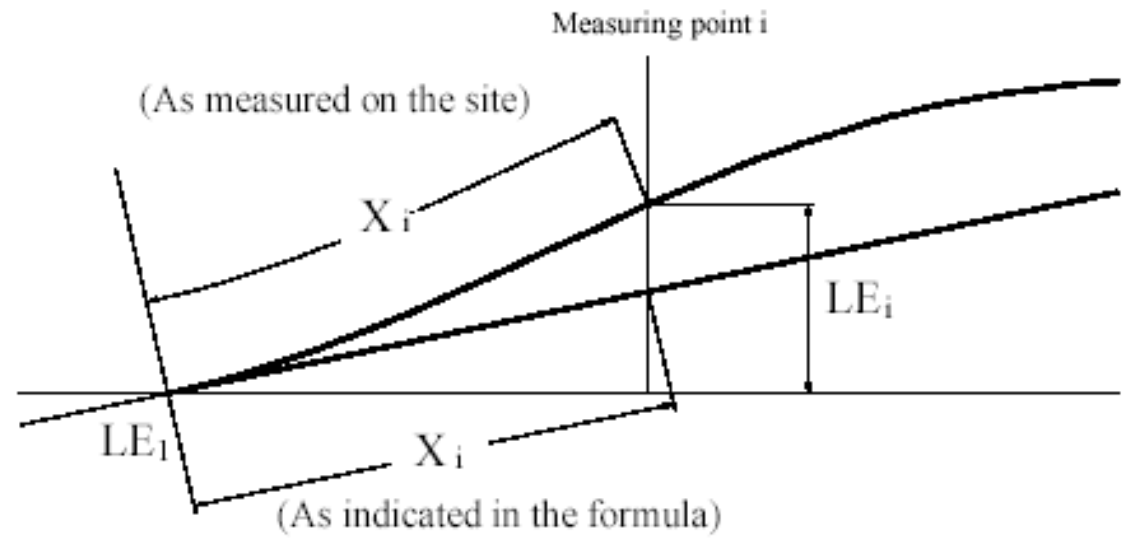

(a)

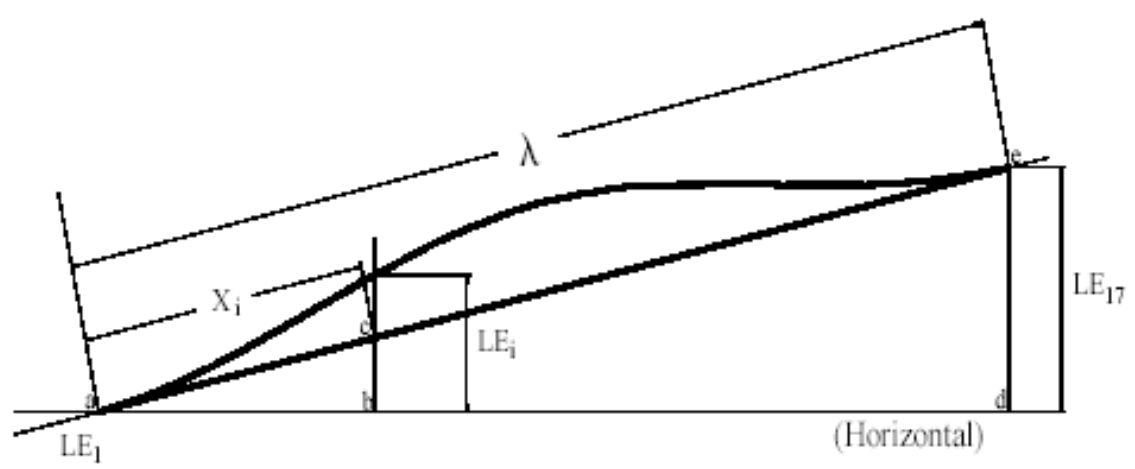

(b)

Figure 2: (a) Approximation of the $\mathrm{x}$-coordinate. (b) Definition of the y-coordinate.

The x-coordinates of the points are measured with a measuring-tape along the surface of the raised construction. Thus, they form an approximation of the real Cartesian coordinates, illustrated in Fig. 2(a). 
The height features of the level form the y-coordinates. However, the $y$-coordinates measured with the level need to be corrected with the formula (1) to compare the measured speed hump with the theoretical horizontal prescribed speed hump in Fig. 2(b).

$$
Y_{i}=\left(L E_{i}-L E_{1}\right)-\left(L E_{17}-L E_{1}\right) * \frac{X_{i}}{\lambda}
$$

Measuring of a plateau is done in a similar way. However the y-coordinate is determined differently (from formula (1), but is also corrected for the slope of the road, which results in formula (2))

$$
Y_{i}=\left(L E_{i}-L E_{1}\right)-\left(L E_{1}-A-L E_{0}\right) * \frac{X_{i}}{X_{0}}
$$

\subsection{Measure method with a total station}

The use of a total station implies the measurement of the points on each wheel track immediately in coordinates (differently from the former method based on a level, where lengths and heights are measured and coordinates are calculated).

However this results in a problem since the obtained coordinates do not form a straight line (in plan view).

Therefore the following solution is applied: first all points (in plan view) are projected on a straight line and their corresponding height is added (Fig. 3).

Secondly, these values are reflected in a profile from which the coordinates can be deduced and processed.

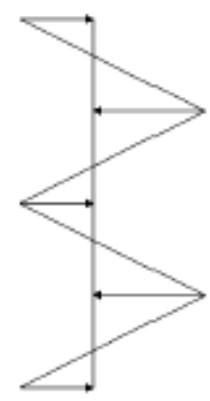

Figure 3: Hypothetic example of a plan view of the profile. 


\subsection{Measure method with GPS}

Since GPS measurements also result in coordinates for all the measuring points, further processing is similar as described above for the total station.

\section{Comparison the measure methods}

Measurements of some randomly chosen speed humps and plateaus on site were performed with respectively a level with an optical micrometer, a total station and a GPS receiver. After processing the results, the following conclusions were drawn:

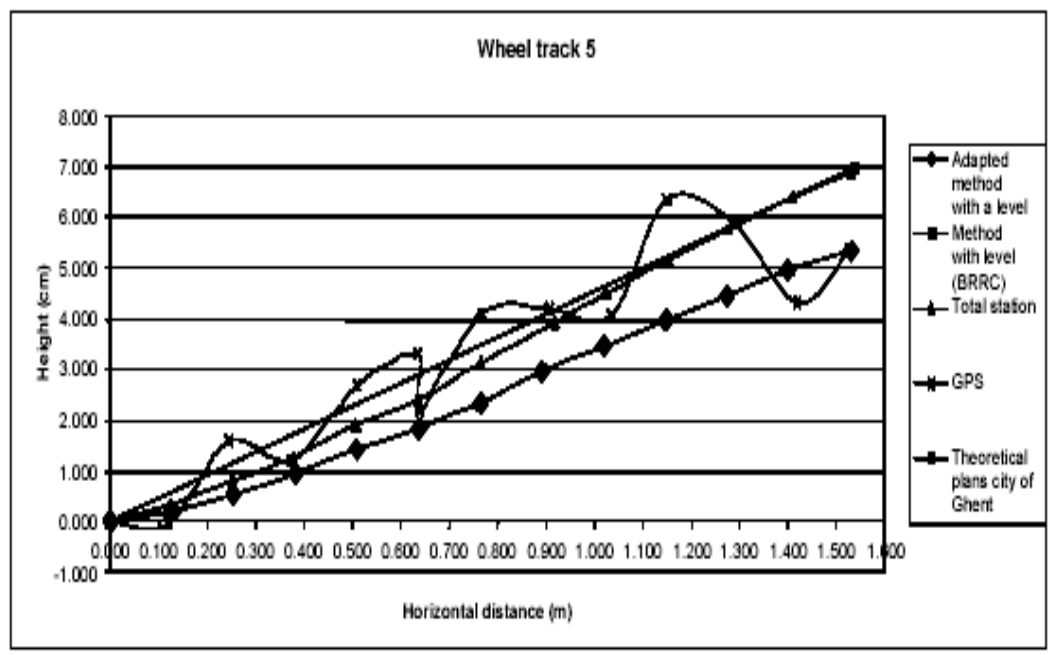

Figure 4: Visual comparison of the measure methods.

- $\quad$ for the Z-coordinate, the results obtained from GPS measurements turned out not to be acceptable since major deviations were observed (Fig. 4).

- $\quad$ important differences (up to $2,5 \mathrm{~cm}$ ) were seen between the method with a level from the BRRC and method with total station. This deviation is due to the use of a different slope for the correction of the coordinates.

- an important result is that the method with total station and the adapted method with level turned out to be highly comparable. With a total station no approximations are used since Cartesians coordinates are obtained. In contrast, the levelling method makes use of approximations but altitude measuring is more precise. 


\section{Road safety aspects}

Some potential impacts are:

- $\quad$ no effect on non-emergency accesses

- $\quad$ speeds determined by height and spacing, speeds between humps have been observed to be reduced between 20 and $25 \%$ on average.

- based on a limited sample of sites, typical crossing speeds $\left(85^{\text {th }}\right.$ percentile) of $30 \mathrm{~km} / \mathrm{h}$ for $10 \mathrm{~cm}$ high $-3,65 \mathrm{~m}$ humps and of 35 $\mathrm{km} / \mathrm{h}$ for $7,50 \mathrm{~m}$ high $-4,25 \mathrm{~m}$ humps, speeds have been observed to rise to $50 \mathrm{~km} / \mathrm{h}$ within $60 \mathrm{~m}$ downstream.

- $\quad$ speeds typically increase approximately $1 \mathrm{~km} / \mathrm{h}$ midway between humps for each 2,50 m of separation.

- studies indicate that collisions have been reduced on average by $13 \%$ on treated streets (not adjusted for traffic diversion).

- most communities limit height to 7,50-10 cm, partly because of harsh ride over $10 \mathrm{~cm}$ high humps.

- possible increase in traffic noise from braking and acceleration of vehicles, particularly buses and trucks.

Emergency response issues are:

- concern over jarring of emergency rescue vehicles

- approximate delay of between 3 and 5 seconds per hump for fire trucks and up to 10 seconds for ambulances with patient.

\section{Conclusions}

It is possible to define the possibility of passing traffic humps or plateaus with a flatbed truck. Mostly, trial and error methods are necessary, which means that the control is labour consuming. But, it is better to do this work and avoid accidents and human harm.

Not all the above proposed and tested methods are restrained.

After comparing the different measurement methods, the measurement method with total station and the adapted method with level, which gives comparable results, were acceptable.

The measurement method with GPS shows too much deviation in the Zcoordinate; the measurement method with level from the BRRC uses another angle of inclination and that is why these methods are rejected.

\section{References}

[1] BRRC, Mode opératoire: contrôle de la géometrie des dispositifs surélevés sur la voie publique. Ralentisseurs de trafic et plateaus, OCW, Sterrebeek 2003.

[2] Van Belleghem D., Van Meulebroeck B., Geometrische en veiligheidsaspecten van verhoogde inrichtingen op de openbare weg. Verkeersdrempels en verkeersplateaus. Ghent Faculty of Sciences - 
632 Urban Transport XIII: Urban Transport and the Environment in the 21st Century

Department of Geography - Division Geomatic Engineering - Surveying - Ghent University 2004.

[3] Belgische wetteksten, Koninklijk besluit tot bepaling van de vereisten voor de aanleg van verhoogde inrichtingen op de openbare weg (bestemd om de maximumsnelheid te beperken tot $30 \mathrm{~km} / \mathrm{h}$ ) en van de technische voorschriften waaraan die moeten voldoen. http://verkeerweb.be/ drempels/drempels.html

[4] Ministerie van de Vlaamse gemeenschap, Ruimtelijk Structuurplan Vlaanderen. http://www2.vlaanderen.be/ned/sites/ruimtelijk/index.html 